\title{
As primeiras indústrias, a arquitetura utilitária e o espaço fabril em Santa Cruz do Sul
}

\author{
Camila Prus ${ }^{1}$ \\ Daniela Elisa Rachor ${ }^{1}$ \\ Milton Roberto Keller ${ }^{2}$ \\ Doris Maria Machado de Bittencourt ${ }^{2}$
}

\section{RESUMO}

O objetivo do presente trabalho é descrever a história da indústria de sua origem até 1930, destacando o vínculo colono-industrialização, a origem dos primeiros estabelecimentos industriais, os condicionantes para o desenvolvimento da mesma, a arquitetura empregada nos prédios fabris e sua situação atual. $\mathrm{O}$ trabalho baseou-se em análises de imagens encontradas nos arquivos do Centro de Documentação da Universidade de Santa Cruz do Sul (CEDOC), e fontes bibliográficas constituídas por livros, jornais, periódicos e meio eletrônico. Dessa forma, o trabalho permite entender o contexto histórico e a dinâmica pela qual a cidade e a indústria foram estruturando-se no território santa - cruzense, como também, identificar e analisar as edificações da arquitetura industrial e como a mesma se relaciona/relacionou com a paisagem urbana.

Palavras-chave: Colonização. Industrialização em Santa Cruz do Sul. Arquitetura industrial. Espaço fabril. Aspectos arquitetônicos. Santa Cruz do Sul.

\begin{abstract}
The purpose of this study is to describe the origin industry history until 1930, contrasting the colonial-industrialization entail, the origin of the first industrial establishments, the conditions for its progress, the architecture employed in industrial buildings and its current situation. The work was based on images analysis found in the archives on Documentation Center of the University of Santa Cruz do Sul, and bibliographical sources consisting in the books, newspapers, magazines and a websites. Therefore, this work search to understand the history and dynamics context in which the city and the industry were being structured in the Santa Cruz city territory, but also identify and analyze the building of industrial architecture and how it relates / related to the urban landscape.
\end{abstract}

Keywords: Settlement. Industrialization in Santa Cruz do Sul. Industrial Architecture. Factory Space. Architectures Aspects. Santa Cruz do Sul.

\footnotetext{
${ }^{1}$ Alunas do Curso de Arquitetura e Urbanismo da Universidade de Santa Cruz do Sul - UNISC.

${ }^{2}$ Professores do Departamento de Engenharia, Arquitetura e Ciências Agrárias na Universidade de Santa Cruz do Sul.<dbitt@terra.com.br>
} 


\section{INTRODUÇÃO}

Este trabalho é parte do projeto de pesquisa "A arquitetura industrial na República Velha: o caso de Santa Cruz do Sul", coordenado pela Professora Dra. Doris Maria Machado de Bittencourt e pelo Professor Me. Milton Roberto Keller.

O trabalho tem por objetivo o estudo do processo de formação e desenvolvimento da indústria e análise de exemplares arquitetônicos representativos do patrimônio arquitetônico industrial santa-cruzense no período da República Velha (1889-1930); considerando que o processo de nascimento da indústria e sua arquitetura estiveram ligados ao processo de imigração-industrialização.

Serão apresentados maiores detalhes de seis exemplares representativos do patrimônio arquitetônico industrial de Santa Cruz do Sul, são eles: Máquinas Binz, Tatsch \& Cia, Cia de Fumos Santa Cruz e Torres \& Cia.

Para a elaboração deste trabalho, foram estudados desde a história de vida dos proprietários, até o seu sistema construtivo dos prédios industriais, bem como sua situação atual. A arquitetura utilitária e o espaço fabril dos mesmos serão exibidos através de desenhos arquitetônicos e levantamentos fotográficos. Serão apresentados também os levantamentos realizados sobre as condições atuais das edificações que não foram demolidas, apresentadas através de fichas de leitura.

Esse tipo de abordagem já foi realizado por autores como Gunter Weimer, Luiz Schneider, Ronaldo Wink, Milton Roberto Keller, Sandra Pesavento, Andrius Estevan Noronha e Silvana Krause. Os quatro primeiros tem se dedicado à pesquisa de História da Arquitetura, notadamente no Rio Grande do Sul. A professora Sandra Pesavento publicou inúmeros livros, resultado de suas pesquisas relacionando história e condições sócioeconômicas no estado do Rio Grande do Sul. Finalmente Krause e Noronha possuem pesquisas que valorizam a história familiar e o surgimento das "belas famílias" em Santa Cruz do Sul, destacando a formação da elite santa-cruzense e das indústrias. 


\section{FUNDAMENTAÇÃO TEÓRICA}

\subsection{Santa Cruz do Sul: origem e colonização alemã}

A origem de Santa Cruz do Sul está ligada à política do governo imperial, durante o século XIX, cujo objetivo era promover a colonização do sul do Brasil com imigrantes europeus, entre estes, os alemães.

A promoção desse fluxo imigratório para o sul do Brasil tinha como objetivo a ocupação e o povoamento de regiões até então desocupadas e distantes, geralmente da área de influência do latifúndio gaúcho e favorecer o desenvolvimento da agricultura e economia do estado, através do emprego de mão-de-obra livre dos colonos migrantes.

Ronaldo Wink ressalta, em Santa Cruz do Sul: urbanização e desenvolvimento ${ }^{3}$, que a vinda dos imigrantes para o sul do Brasil tinha como objetivo satisfazer uma série de necessidades e interesses, tanto do governo imperial e provincial, como dos próprios imigrantes, oriundos de uma Europa em grandes transformações sociais, políticas e econômicas.

Para uma contextualização geral e melhor entendimento dos fatores e acontecimentos que marcaram a história da cidade, dividimos o processo de evolução urbana de Santa Cruz do Sul em quatro fases ou períodos históricos, seguindo o modelo teórico de análise já aplicado por Ronaldo Wink e por Silvana Krause em Migrantes do Tempo: vida econômica, política e religiosa de uma comunidade de imigrantes alemães na República Velha ${ }^{4}$.

\section{$2.21^{\text {a }}$ fase - povoação a freguesia (1849 - 1859)}

O núcleo colonial de Santa Cruz do Sul iniciou com a chegada dos primeiros imigrantes alemães em dezembro de 1849. Esta fase tem como característica uma economia de subsistência, o fumo já era plantado na colônia. Segundo Jorge Luis da Cunha, o crescimento da colônia acontece especialmente depois de 1854, com a regulamentação da Lei de Terras e com a Lei Provincial $n^{\circ} 304$, que "obriga" os imigrantes a pagar pelos lotes coloniais e pelas despesas que o governo teve com o transporte e subsídios dos imigrantes.

\footnotetext{
${ }^{3}$ WINK, Ronaldo. Santa Cruz do Sul: urbanização e desenvolvimento. 1. ed. Santa Cruz do Sul: EDUNISC, 2002. 179 p.

${ }^{4}$ KRAUSE, Silvana. Migrantes do tempo: vida econômica, política e religiosa de uma comunidade de imigrantes alemães na República Velha. Santa Cruz do Sul: EDUNISC, 2002.
} 


\section{$2.32^{\mathrm{a}}$ fase - freguesia a vila $(1859-1878)$}

Sob efeito da Lei Provincial $n^{\circ}$ 304, ocorreu o aumento da produção e da diversificação da agricultura colonial, estruturação do artesanato e comércio, este último impulsionado pelas trocas de excedentes agrícolas por produtos manufaturados. Esse processo, vinculado à localização privilegiada da freguesia e a melhora dos meios de transporte, proporcionou aos comerciantes acumulo de capital, através da intermediação dos produtos dos colonos da localidade e de outros mercados.

\section{$2.43^{\text {a }}$ fase - acumulação do capital (1878 - 1917)}

Predomínio da cultura do fumo na produção e exportação. Vila elevada à categoria de cidade (1905). Nesse período a construção do ramal ferroviário facilitou a circulação das mercadorias produzidas na região e aumentou o ritmo das exportações, intensificou o acumulo de capital por parte dos comerciantes. Em consequência houve a fundação do primeiro banco na cidade (Caixa Santa-Cruzense), a implantação e melhorias da infraestrutura urbana, tudo isso influenciou o surgimento e desenvolvimento das primeiras indústrias, atraindo também a primeira empresa de capital estrangeiro (British American Tobacco) e outras atividades comerciais na região.

\section{$2.54^{\text {a }}$ fase - industrialização (1917 - 1930)}

Esta fase prolonga-se até 1965 (nosso estudo abrangerá até 1930) e é estruturada pela consolidação e expansão do capitalismo, principalmente do ramo fumageiro, na economia da cidade. Novas tecnologias, como a secagem em estufas e o plantio de diferentes tipos de fumo influenciaram no impulso desta economia.

Após um panorama sobre a evolução urbana de Santa Cruz do Sul até 1930, cabe-nos refletir e analisar sobre uma questão: Qual foi a origem do capital industrial em Santa Cruz do Sul, ou melhor, como surgiram as primeiras indústrias no município?

\subsection{A arquitetura utilitária e o espaço fabril}

De acordo com Günter Weimer em, A vida cultural e a arquitetura na República Velha rio-grandense: $1889-1945 .{ }^{5}$, o período de pós-guerra fez com que os países europeus ficassem

\footnotetext{
${ }^{5}$ WEIMER, Günter. A vida cultural e a arquitetura na República Velha rio-grandense: 1889-1945. Porto Alegre: EDIPUCRS, 2003. $328 \mathrm{p}$
} 
destruídos e com suas economias retraídas. A partir de então, a arquitetura evoluiria rapidamente para a sua simplificação. ${ }^{6}$

Devido a este fato, a arquitetura no Brasil também foi influenciada, as indústrias passaram a ser construídas com um estilo arquitetônico simplificado e econômico, uma arquitetura utilitária, visando a racionalização dos espaços industriais e contornando os problemas de organização espacial.

O novo estilo arquitetônico utilizado pelos imigrantes, o "Neue Sachlichkeit", ou Nova Objetividade, empregado na arquitetura utilitária, caracteriza um funcionalismo formal e simplificação arquitetônica. A Nova Objetividade foi um estilo que antecipou a racionalização formal do Movimento Modernista no estado. Era uma tendência utilizada nesse período pelos arquitetos na Alemanha e que com a vinda dos imigrantes chegou até Santa Cruz do Sul. Tinha por objetivo a racionalização expressiva das formas arquitetônicas, fazia restrição ao uso da arte decorativa nas edificações, e o uso de decoração deveria ter razão objetiva para seu emprego. Com relação ao espaço fabril, é o espaço arquitetônico construído que abriga e organiza as diversas atividades realizadas dentro da indústria.

O espaço fabril busca determinar um significado para a configuração do espaço construído - sua inserção no espaço urbano e localização. A arquitetura utilitária busca estabelecer um significado à configuração espacial da fábrica - no sentido de sua localização em relação à mão-de-obra, acessos (sistema viário), matéria prima, comercialização - dentro do sistema econômico. ${ }^{7}$

\section{METODOLOGIA}

Esta pesquisa está sendo desenvolvida através de saídas de campo, levantamento fotográfico, arquitetônico e físico-visual dos prédios utilitários existentes, análises de fotografias e documentos históricos do Centro de Documentação da Universidade de Santa Cruz do Sul (CEDODC), pesquisas em fontes bibliográficas constituídas por manuscritos, livros, jornais e periódicos. Abordou-se também o estudo do surgimento dessas edificações, bem como o seu desenvolvimento e os movimentos de imigração no local.

A partir da seleção dos prédios, realizou-se entrevistas com pessoas ligadas a história das edificações, estes revelando detalhes que serviram também de embasamento para os textos do projeto.

\footnotetext{
${ }^{6}$ WEIMER, Günter. Arquitetura modernista em Porto Alegre: entre 1930 e 1945. Porto Alegre: UE, 1998, p. 20

${ }^{7}$ CRUZ, Glenda Pereira da. Espaço Construído e Formação Econômico Social do Rio Grande do Sul, v1, p. 20.

Tese de Mestrado submetida ao PROPUR, 1982.
} 


\section{RESULTADOS}

\subsection{MÁQUINAS BINZ}

Localizava-se na Rua Tenente Coronel. Brito, 425; foi construído em $1927^{8}$; tendo como empreendedor Rodolfo Binz e atualmente está em bom estado de conservação.

\subsubsection{Histórico}

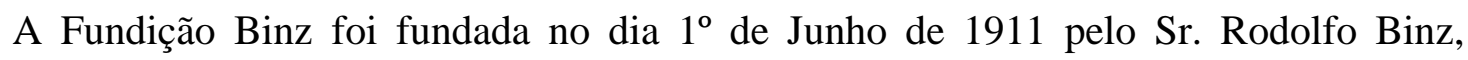
sucessor de José Binz. A especialidade da indústria era fundição e trabalhos de metais para diversos ramos. O prédio mais significativo do empreendimento foi construído em 1927.

\subsubsection{Aspectos arquitetônicos}

A edificação faz parte do conjunto de edificações que definiram a introdução da linguagem industrial no espaço urbano da cidade. O conjunto é composto de vários blocos, sendo a construção original o volume que apresenta o frontão na fachada principal. O prédio mais significativo possui uma fachada simétrica com poucas aberturas e o acesso principal único, no centro. Observa-se o uso de vergas em arco pleno nas janelas, sendo as superiores de vidro e com bandeiras fixas.
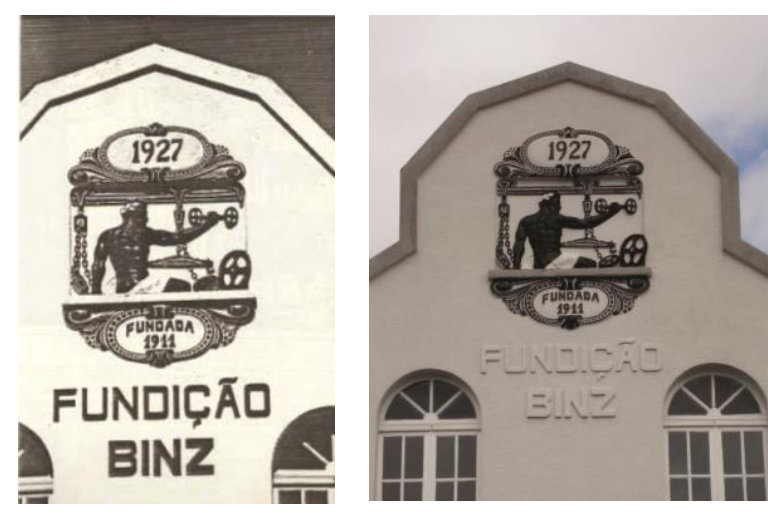

O frontão principal possui um formato diferenciado em baixo relevo em bronze, encobre também o telhado, que possui grande inclinação para o melhor escoamento da águas pluviais. O emblema em bronze da fundição representa Hefesto, deus grego do fogo, dos metais e da metalurgia.

\footnotetext{
${ }^{8}$ Inventário do Patrimônio Arquitetônico, Santa Cruz do Sul 2003.
} 


\subsubsection{Levantamento fotográfico}

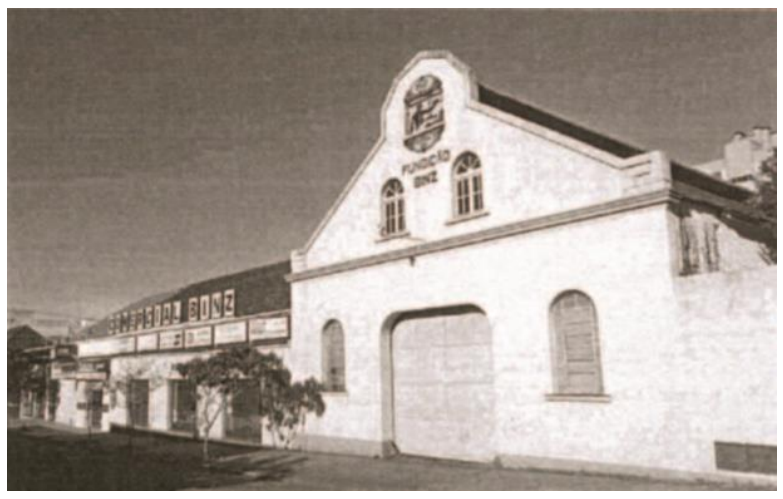

MÁQUINAS BINZ - Foto do conjunto em 1927

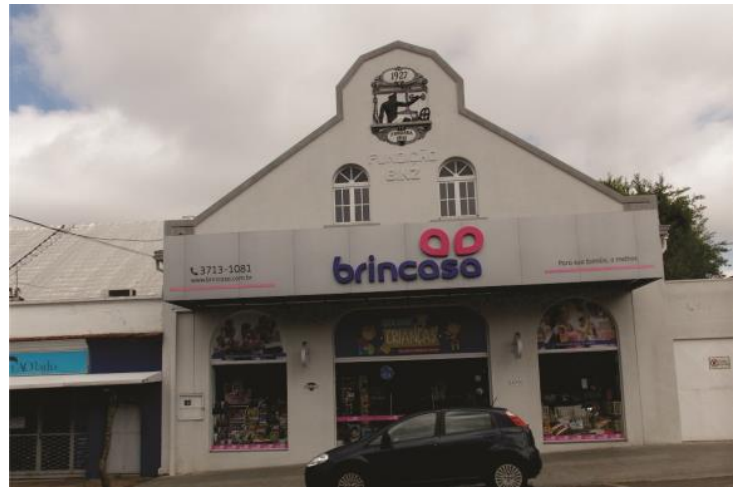

MÁQUINAS BINZ- Foto atual do conjunto

\subsubsection{Levantamento físico-visual}

Partindo de levantamentos fotográficos, em conjunto com o auxílio das plantas originais foi possível a compreensão do sistema construtivo e a representação atualizada do mesmo proporcionando melhor leitura do projeto arquitetônico e sua importância de sua preservação.

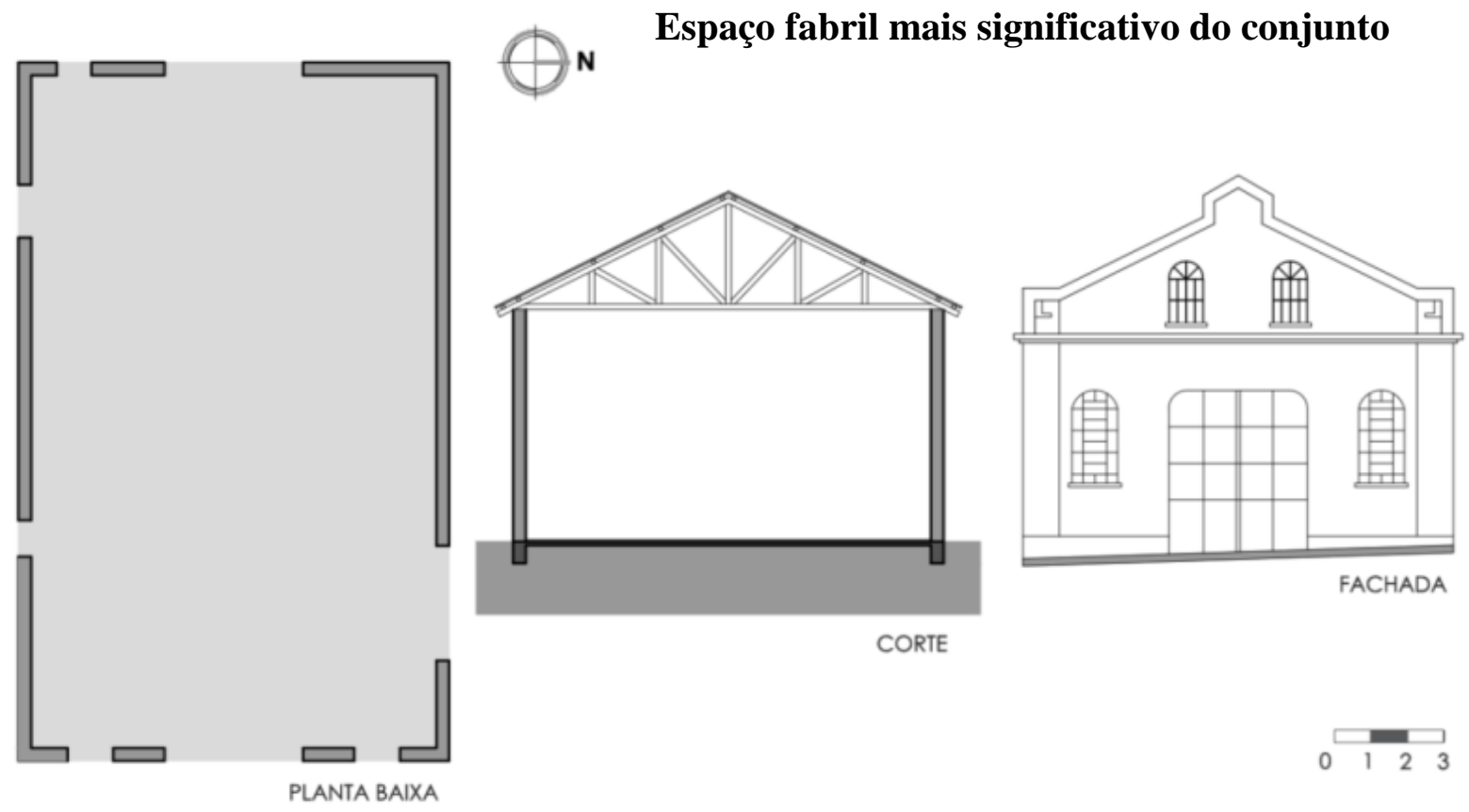




\subsection{TATSCH \& CIA}

Localizava-se na Rua Ernesto Alves, esquina com a Fernando Abott, foi construído em $1922^{9}$, tendo como empreendedor Fernando C. Tatsch, como projetista Henrique Schutz e atualmente apresenta muitas modificações em comparação à sua forma original.

\subsubsection{Histórico}

Inicialmente a fábrica da família Tatsch, produzia somente banha, mais tarde passou a comercializar "secos e molhados" sob a forma de atacado. Entre as décadas de 30 e 40 o comércio de secos e molhados foi substituído por uma fábrica de cigarros da família Tatsch. As instalações sofreram modificações restando poucas características da antiga fábrica de banhas. Em1976 a fábrica é vendida para uma multinacional, encerra seu funcionamento e ocorre a partilha dos bens entre os filhos homens de Fernando C. Tatsch, a quem o conjunto pertence até hoje.

\subsubsection{Aspectos arquitetônicos}

O projeto original possuía somente o pavimento térreo, o segundo pavimento surgiu na década de 40-50 quando já havia o comércio e depósito de fumos.

As edificações existentes no lote estão descaracterizadas da edificação original, muitos elementos foram substituídos, como por exemplo, as esquadrias. A edificação possui coroamento em platibanda.

\subsubsection{Levantamento fotográfico}

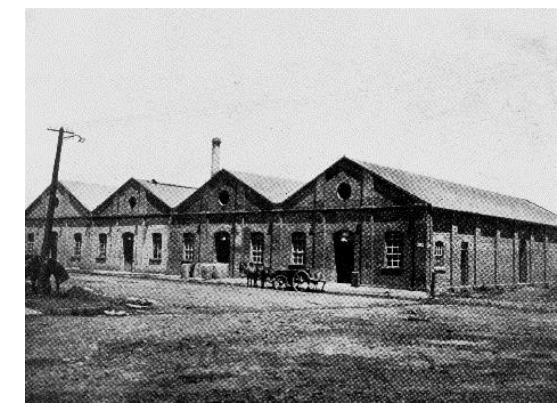

TATSCH E CIA - Foto do conjunto em 1922

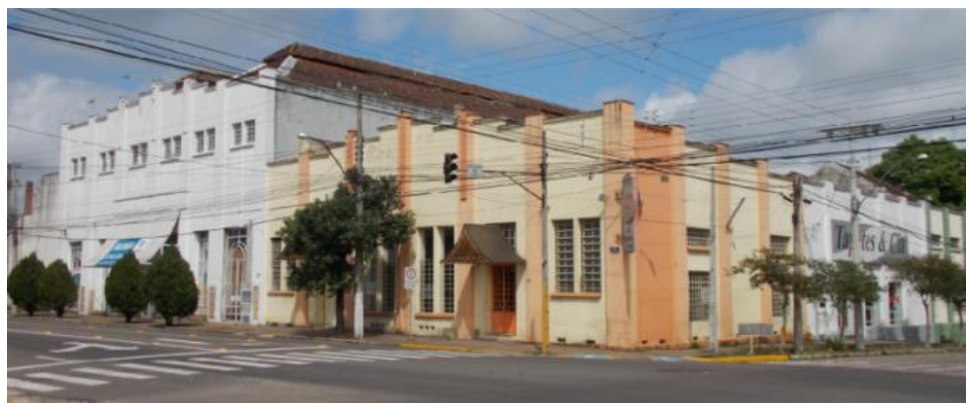

TATSCH E CIA - Foto atual do conjunto

\footnotetext{
${ }^{9}$ Inventário do Patrimônio Arquitetônico, Santa Cruz do Sul 2003.
} 


\subsubsection{Levantamento físico-visual}

Partindo de levantamentos fotográficos, em conjunto com o auxílio das plantas originais foi possível a compreensão do sistema construtivo e a representação atualizada do mesmo proporcionando melhor leitura do projeto arquitetônico evidenciando a importância e necessidade de sua preservação.

LEGENDA:

área coberta área aberta
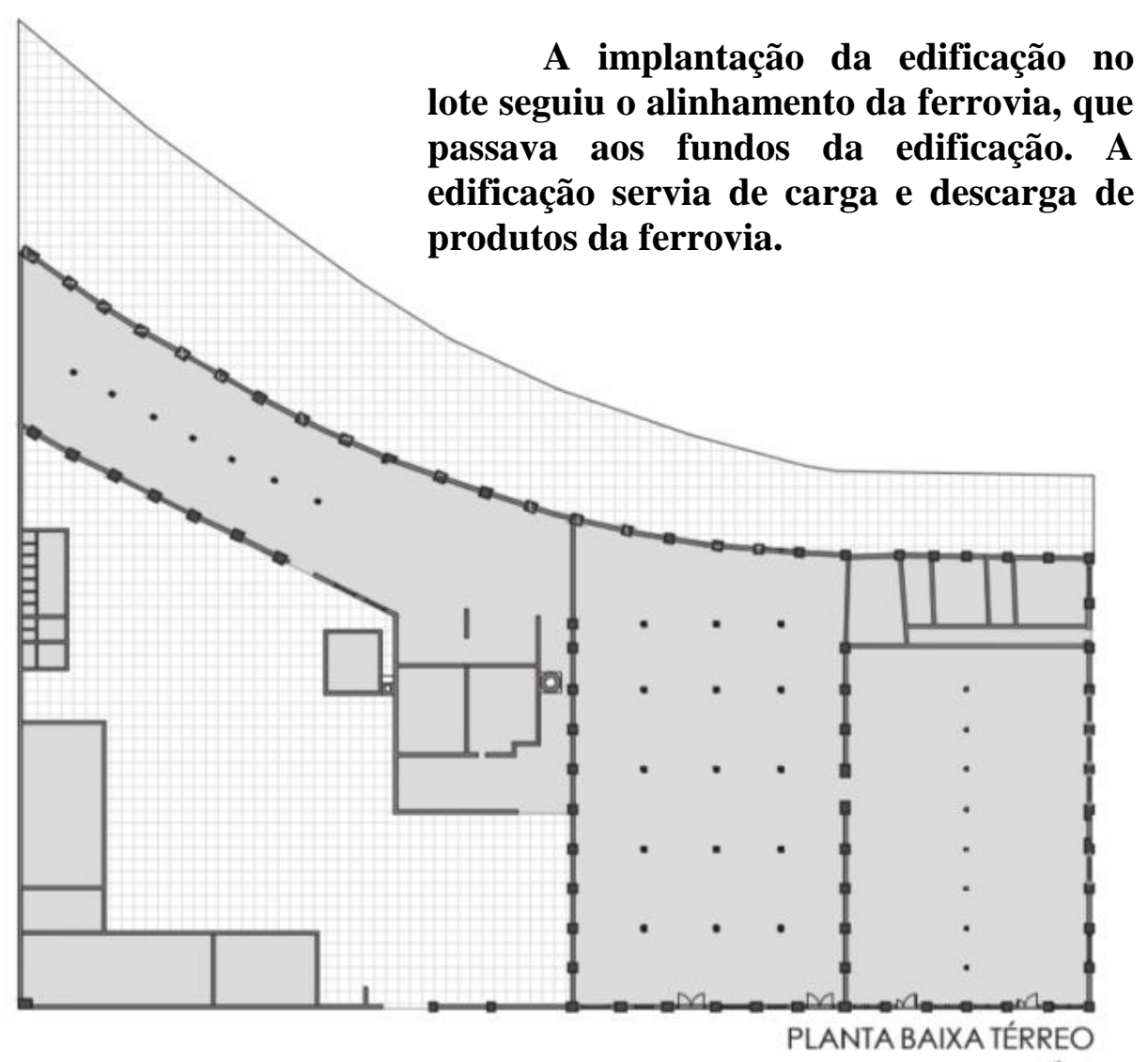

$\underset{0246}{24}$

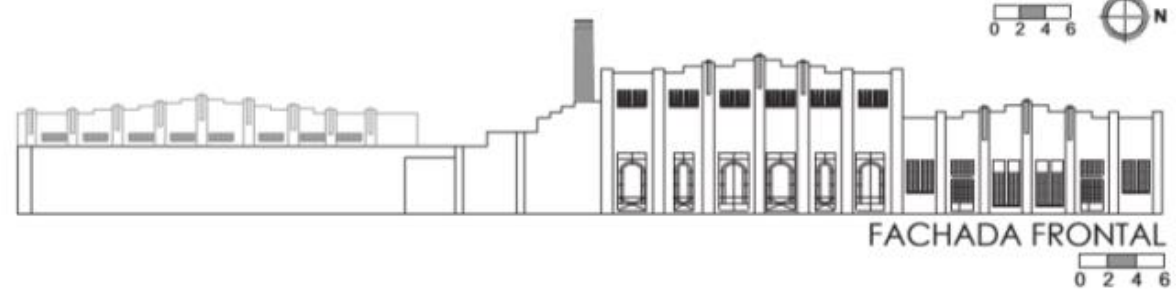

\subsection{CIA DE FUMOS SANTA CRUZ}

Localizava-se na Rua Borges de Medeiros, 929, foi construída entre 1922 e 1923, tendo como empreendedor a Companhia de Fumos Santa Cruz e a edificação foi demolida em 2014.

\subsubsection{Histórico}

Após a Segunda Guerra Mundial a indústria em Santa Cruz do Sul teve que encarar um processo maior de competitividade, revelando uma nova fase. Foi o caso da Companhia 
de Fumos Santa Cruz, em 28 de dezembro de 1918. Foi resultado da fusão de seis estabelecimentos do ramo de tabaco em Santa Cruz do Sul, onde o objetivo era unir suas forças como alternativa para uma nova fase industrial. São eles: Irmãos Schütz (de Helmuth e Alfred), Lindolfo Grawunder, Schilling\&Cia, J. N. Kliemann, José Etges Filho \& Cia e Adolfo Iserhard. ${ }^{10}$

\subsubsection{Aspectos Arquitetônicos}

Embora o estilo arquitetônico adotado no 'espaço fabril' em 1923 seja mais comprometido com o ecletismo, a reforma posterior denota a ao estilo da Nova Objetividade ou Sachlichkeit, uma arquitetura simplificada, empregada pelos imigrantes alemães e seus descendentes. Foi um estilo arquitetônico que antecipou o Movimento Modernista no estado. A edificação é caracterizada por possui três pavimentos, com pé direito alto, frontões e aberturas sequenciais, que foram definidas pela marcação vertical da fachada através de pilastras

Infelizmente a edificação foi demolida no ano de 2014, para a construção de um conjunto habitacional.

\subsubsection{Levantamento fotográfico}

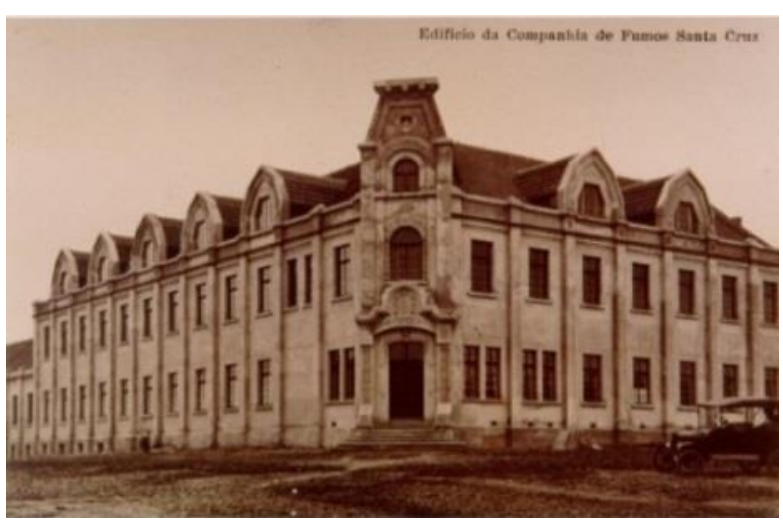

Edificação original da Companhia na esquina das ruas Borges de Medeiros e Ernesto Alves. Ano de 1923

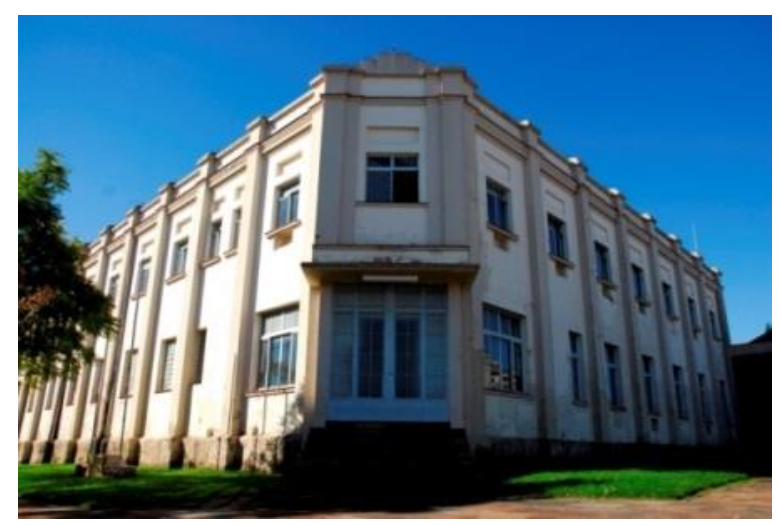

Novas instalações nas esquinas das ruas Borges de Medeiros e Ernesto Alves, em 2014.

\footnotetext{
${ }^{10}$ LUDWIG, Alfredo. 1849-1949. Centenário da Colonização de Santa Cruz do Sul. Manuscrito Original do Arquivo Histórico do Colégio Mauá.
} 


\subsubsection{Levantamento físico-visual}

Partindo de levantamentos fotográficos, em conjunto com o auxílio das plantas originais foi possível a compreensão do sistema construtivo e a representação de como se configurava o edifício. Levando em consideração que não mais é possível fazer conferências no local, pois o mesmo foi demolido.

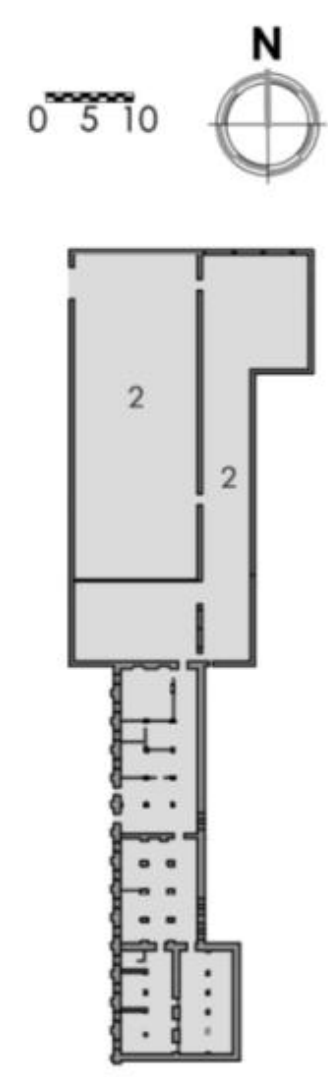

PLANTA BAIXA SUBSOLO

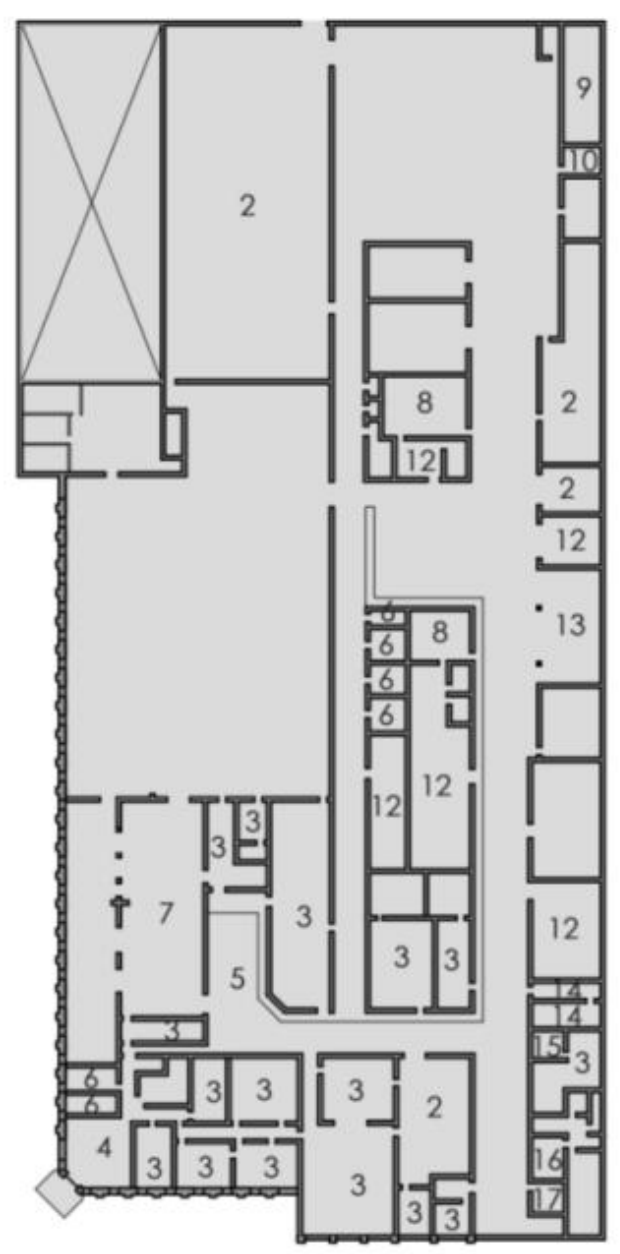

PLANTA BAIXA TÉRREO

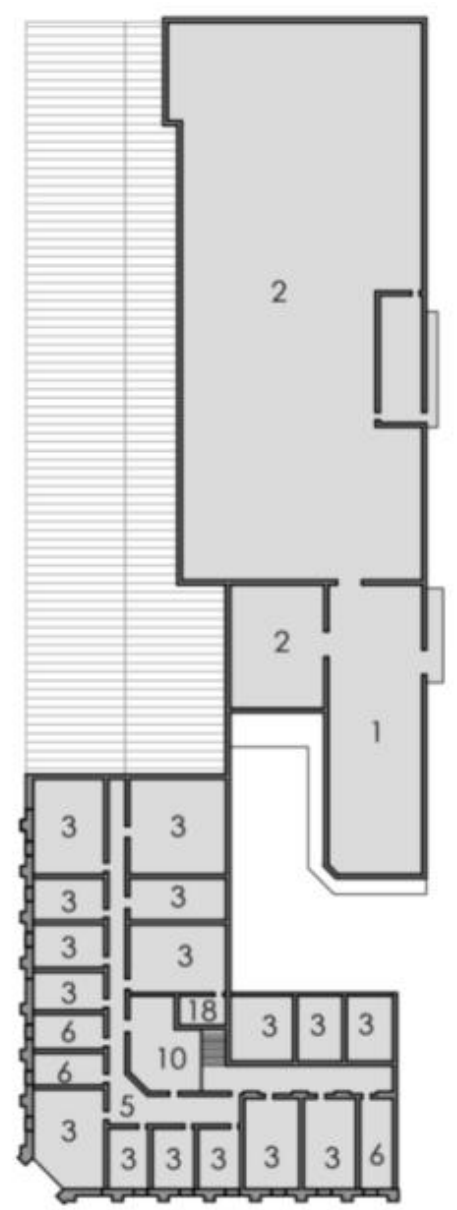

PLANTA BAIXA $2^{\circ}$ PAVIMENTO

\subsection{TORRES \& CIA}

Localizava-se na Rua Ramiro Barcelos, 1403 e 1421, foi construído em $1927^{11}$, tendo como empreendedor Torres \& Cia e atualmente apresenta-se em bom estado de conservação.

\footnotetext{
${ }^{11}$ Inventário do Patrimônio Arquitetônico, Santa Cruz do Sul 2003.
} 


\subsubsection{Aspectos arquitetônicos}

O Conjunto é formado por quatro pavilhões simetricamente dispostos no alinhamento frontal do terreno. O pavimento térreo possui pé direito alto o que proporciona esquadrias alongadas na vertical, no sótão da edificação observa-se janela em arco pleno no centro de cada conjunto. O frontão é marcado por linhas semi-circulares que suavizam a grande extensão do conjunto.

A marcação vertical é dada pelas meias colunas apoiadas em na base em modernatura da edificação, onde frisos horizontais também fazem composição ao conjunto. As esquadrias são divididas pela localização das meias colunas, onde a porta principal de cada pavilhão possui uma grande dimensão e fica localizada no eixo central e dá acesso ao inteior.

A harmonia do conjunto garante uma grande imponência, valorizado por sua plasticidade sóbria.

\subsubsection{Levantamento fotográfico}

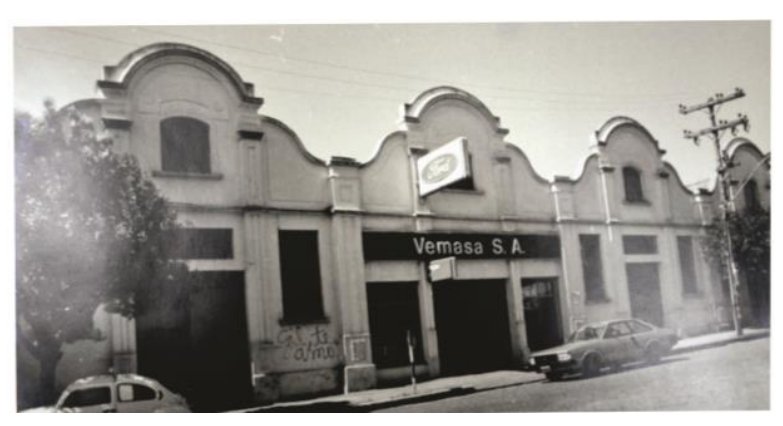

TORRES E CIA - Foto do conjunto em 1927

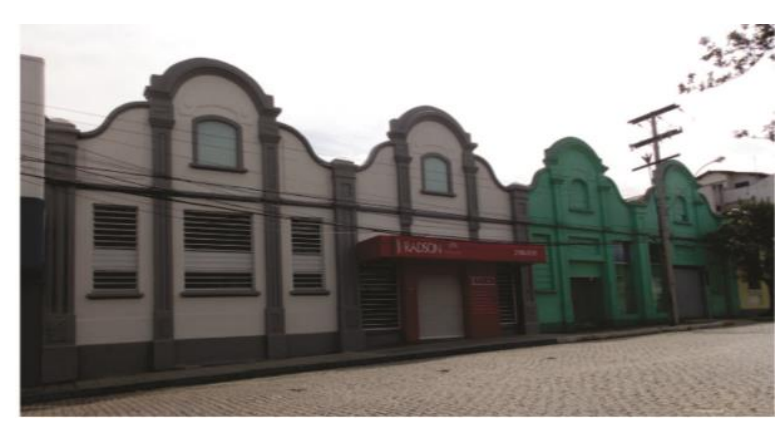

TORRES E CIA - Foto atual do conjunto

\subsubsection{Levantamento físico-visual}

Partindo de levantamentos fotográficos, em conjunto com auxílio das plantas originais foi possível a compreensão do sistema construtivo e a representação atualizada do mesmo proporcionando melhor leitura do projeto arquitetônico e sua importância de sua preservação. 


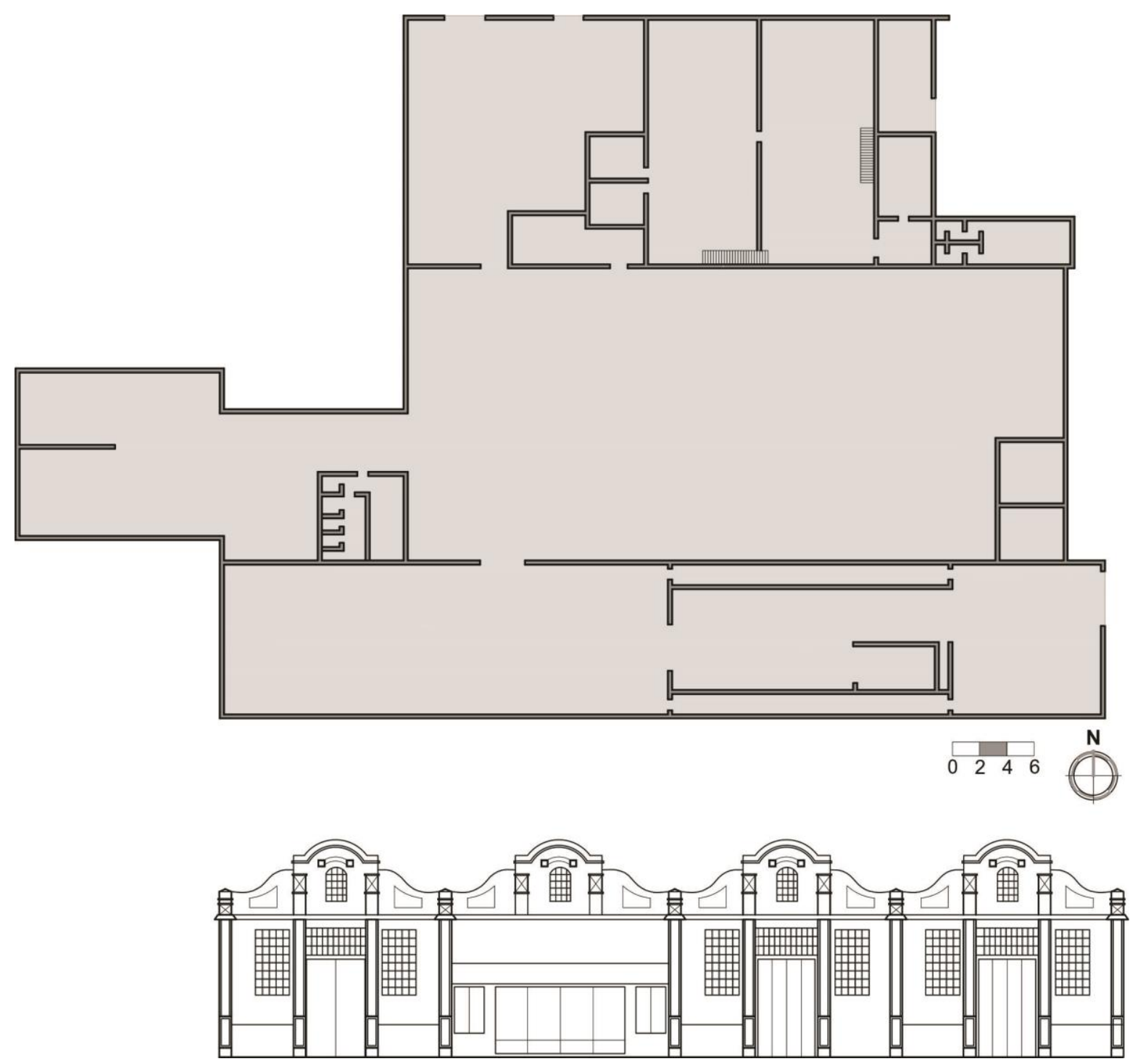

TORRES E CIA -

Planta baixa e

fachada Sul

\section{CONSIDERAÇÕES}

A divulgação e a valorização dos edifícios que fazem parte do Patrimônio Arquitetônico de Santa Cruz do Sul, ressaltando a importância do estudo e documentação das edificações que fazem parte da cultura e história de Santa Cruz do Sul.

Levantamento fotográfico e arquitetônico das edificações, juntamente com entrevistas e relatos das pessoas ligadas à história. Fichas técnicas para documentação de dados mais aprofundados de cada obra selecionada. 
O projeto de pesquisa foi apresentado no XVI Salão de Iniciação Científica da PUCRS e no XXI Seminário de Iniciação Científica da UNISC, através da composição de slides com os objetivos, as atividades realizadas e resultados obtidos.

Finalizando, o projeto recebeu uma premiação, Prêmio Destaque da Iniciação Científica - UNISC 2015, trazendo o reconhecimento pelo esforço e dedicação para a realização do trabalho, sendo oferecida a oportunidade para a publicação de um artigo referente ao tema apresentado.

\section{CONCLUSÃO}

Dessa forma, o trabalho permite entender o contexto histórico e a dinâmica através qual a cidade e a indústria se estruturam no território santa-cruzense, bem como também, identificar e analisar as edificações da arquitetura industrial, como a mesma se relaciona/relacionou com a paisagem urbana.

Observou-se que a arquitetura utilitária em Santa Cruz do Sul não emprega excessos decorativos, por sua finalidade utilitária e econômica. Possui característica despojada e autêntica, emprega formas puras e volumes limpos. Conforme as hipóteses iniciais, comprovamos que estas edificações apresentam/apresentaram traços do movimento Sachlichkeit ou Nova Objetividade.

\section{REFERÊNCIAS BIBLIOGRÁFICAS}

CUNHA, J. L. da. Os colonos alemães de Santa Cruz e a fumicultura. Santa Cruz do Sul, Rio Grande do Sul 1849-188. Dissertação de mestrado na UFPR em 1988, Curitiba, Paraná.

CRUZ, G. P. da. Espaço Construído e Formação Econômico Social do Rio Grande do Sul, v1, p. 20. Tese de Mestrado submetida ao PROPUR, 1982.

KELlER, M. R. Santa Cruz do Sul e sua Arquitetura Eclética. 2001. 262 f. Dissertação (Programa de Pós-Graduação de Desenvolvimento Regional - Mestrado e Doutorado) Universidade de Santa Cruz do Sul, Santa Cruz do Sul, 2001.

KRAUSE, S. Migrantes do tempo: vida econômica, política e religiosa de uma comunidade de imigrantes alemães na República Velha. Santa Cruz do Sul: EDUNISC, 2002. 207 p. 
LUDWIG, A. 1849-1949. Centenário da Colonização de Santa Cruz do Sul. Manuscrito Original do Arquivo Histórico do Colégio Mauá.

PESAVENTO, S. História da Arquitetura Sul Rio-grandense. Porto Alegre: Editora Palloti, 1985.

NORONHA, A. E. Beneméritos empresários: História Social de uma elite de origem imigrante do Sul do Brasil (Santa Cruz do Sul, 1905-1966). 2012. 370 f. Tese (Programa de Pós-Graduação em História - Mestrado e Doutorado) - Pontifícia Universidade Católica do Rio Grande do Sul, Porto Alegre, 2012.

REVISTA REDES. 150 anos de Colonização Alemã em Santa Cruz do Sul, 1849-1999. Sínteses Históricas e Estudos. Santa Cruz do Sul: EDUNISC, 1999.

ROCHE, J. A colonização alemã e o Rio Grande do Sul. Porto Alegre: Globo, 1969. v1 A colonização alemã e o Rio Grande do Sul. Porto Alegre: Globo, 1969. v2

WEIMER, G. Arquitetura modernista em Porto Alegre: entre 1930 e 1945. Porto Alegre: UE, 1998. $173 \mathrm{p}$.

WEIMER, G. A vida cultural e a arquitetura na República Velha rio-grandense: 1889-1945. 1. Ed. Porto Alegre: EDIPUCRS, 2003. 328 p.

WINK, R. Santa Cruz do Sul: urbanização e desenvolvimento. 1. ed. Santa Cruz do Sul: EDUNISC, 2002. 179 p.

NÚCLEO DE GESTÃO PÚBLICA. Inventário do Patrimônio Arquitetônico da área central urbano de Santa Cruz do Sul, pesquisa do Curso de Arquitetura e Urbanismo, Universidade de Santa Cruz do Sul - UNISC em parceria com a Prefeitura Municipal de Santa Cruz do Sul, 2006.

COMPANHIA DE FUMOS SANTA CRUZ. A Companhia de Fumos Santa Cruz no $25^{\circ}$ aniversário da fundação 1918-1943. Santa Cruz do Sul: [s.n.] [1943?] 
COMPANHIA DE FUMOS SANTA CRUZ. A Companhia de Fumos Santa Cruz no 50 aniversário da fundação 1969. Santa Cruz do Sul: [s.n.] [1969?]

\section{Como citar este documento:}

PRUS, Camila et al. As primeiras indústrias, a arquitetura utilitária e o espaço fabril em Santa Cruz do Sul. Revista Jovens Pesquisadores, Santa Cruz do Sul, v. 6, n. 2, nov. 2016. ISSN 2237-048X. Disponível em: 〈https://online.unisc.br/seer/index.php/jovenspesquisadores/article/view/7295>. Acesso em: ... doi:http://dx.doi.org/10.17058/rjp.v6i2.7295. 